\title{
A percepção do citricultor sobre a indústria paulista de suco de laranja: parceria ou conflito?
}

\author{
Fernanda Geraldini Palmieri ${ }^{1} \&$ Margarete Boteon ${ }^{1}$ \\ RESUMO
}

A citricultura paulista é uma atividade agrícola bastante importante, principalmente no que diz respeito à fruta destinada à moagem. Por conta do elevado volume produzido no estado, as processadoras têm um papel essencial quanto ao escoamento da fruta; contudo, as relações comerciais entre produtor e indústria, muitas vezes, são conflituosas. O presente trabalho teve como objetivo analisar as percepções de citricultores paulistas sobre a indústria de suco de laranja, tendo em vista os conflitos existentes nesta relação comercial, principalmente em decorrência da estrutura concentrada da indústria, geradora de poder de mercado. A abordagem utilizada é qualitativa e o tipo de estudo descritivo, baseado em entrevistas semiestruturadas realizadas com dez produtores de laranja do estado de São Paulo, sendo que todos comercializam pelo menos parte de sua produção com a indústria e têm no mínimo cinco anos de atuação na atividade citrícola. A análise de conteúdo das entrevistas mostrou que o citricultor avalia a indústria como essencial para a sua atividade, apesar de considerar que a mesma possui alguns aspectos negativos, como a prioridade de negociação com grandes produtores, dificuldade na relação contratual e sua estrutura concentrada, que aumenta o seu poder de mercado e diminui as opções de comercialização dos produtores. Com relação às pequenas indústrias, seu surgimento e crescimento (em número) é visto como positivo por produtores, mas estes ainda não as consideram como solução para a comercialização da laranja, dada a pequena representatividade de sua capacidade instalada frente às grandes indústrias e também pela sua reputação, nem sempre sólida.

Termos de indexação: economia, citricultura, SLCC, concentração.

\section{Citrus grower's perception of Sao Paulo orange juice Industry: partnership or conflict?}

\section{SUMMARY}

Orange sector in São Paulo state is an agricultural activity very important, mainly in the case of fruit processing. The high volume produced in the state, industries have an essential role about fruit flow; however, commercial relations between citrus grower and processors, sometimes, are conflicting. The objective of this study was to analyze the perceptions of citrus growers from the State of São Paulo, Brazil, regarding the orange juice industry, in view of the conflicts in this commercial relationship, mainly due to the concentrated structure of the industry, which generates

\footnotetext{
${ }^{1}$ Centro de Estudos Avançados em Economia Aplicada - CEPEA, Escola Superior de Agricultura "Luiz de Queiroz" - ESALQ, Universidade de São Paulo - USP, Piracicaba, SP, Brasil

Autor correspondente: Fernanda Geraldini Palmieri, Av. Pádua Dias, 11, CP 132, CEP 13400-970, Piracicaba, SP, Brasil. E-mail: fernanda.geraldini.gomes@usp.br
} 
market power. The approach used is qualitative and the type of descriptive study, based on semi-structured interviews conducted with ten orange producers in the state of São Paulo, all of which market at least part of their production with industry and have a minimum of five years of performance in citrus activity. The content analysis of the interviews showed that the citrus grower evaluates the industry as essential for its activity, although it considers that it has some negative aspects, such as the priority of negotiation with large producers, difficulty in contractual relationship and its concentrated structure, which Increases its market power and reduces the producers' marketing options. Regarding small industries, their emergence and growth (in number) is seen as positive by producers, but these still do not consider them as a solution for the commercialization of the orange, given the small representativeness of its installed capacity in front of the big industries and also by the Its reputation, not always solid.

Index terms: economy, citrus, FCOJ, concentration.

\section{INTRODUÇÃO}

O sistema agroindustrial da laranja é um dos mais dinâmicos da economia brasileira (Paulillo, 2006), com grande concentração no estado de São Paulo devido à presença de grandes processadoras da fruta. $\mathrm{O}$ crescimento da produção paulista de laranja acompanhou a instalação e o crescimento das processadoras no estado. Neste cenário, torna-se difícil imaginar a citricultura paulista sem a indústria, já que o mercado de fruta in natura absorve uma pequena parcela da produção do estado. Como consequência, o processamento é o principal destino desta fruta cítrica, com mais de $85 \%$ do total produzido no estado em 2017/18 (CITRUSBR, 2018).

A relação comercial entre produtor e indústria, contudo, possui conflitos, principalmente no que diz respeito à precificação da laranja. As fórmulas de cálculo de preços nem sempre são consideradas transparentes (Ito \& Zylbersztajn, 2016), o que gera um clima de desconfiança da parte de citricultores. $O$ fato de o sistema agroindustrial ser oligopolizado (Paulillo, 1999), por sua vez, faz com que o produtor tenha poucas opções de negociação, com três empresas detentoras da maior parte do mercado (Silva et al., 2017).

Nem mesmo o surgimento de um maior número de pequenas fábricas de processamento de suco de laranja em São Paulo ameniza a grande concentração do setor, já que estas podem ser representativas em número de unidades industriais, mas ainda não o são quando se analisa a capacidade instalada. Desta forma, estas empresas ainda são consideradas como uma opção, mas não uma solução para o oligopsônio do sistema agroindustrial citrícola.

Considerando estes fatores que envolvem o sistema agroindustrial citrícola (elevada concentração industrial, conflitos comerciais entre produtores e processadoras e baixa representatividade das pequenas indústrias), qual a visão do citricultor sobre a indústria paulista de suco de laranja?
Haja vista a grande importância do segmento industrial ao setor produtivo e o desgaste muitas vezes causado por conflitos na relação comercial, o principal objetivo desta pesquisa é verificar a percepção de produtores de laranja com relação à indústria de suco. Como objetivos específicos, busca-se verificar a percepção de citricultores a respeito das grandes indústrias, bem como a visão destes produtores com relação à estrutura concentrada das processadoras paulistas. Também buscou-se analisar a percepção de agricultores quanto às pequenas indústrias de suco de São Paulo, emergentes nos últimos anos, como alternativa de comercialização da laranja.

\section{Citricultura}

No agronegócio brasileiro, a citricultura tem se mostrado uma atividade bastante importante. O País é o maior produtor mundial de laranja, colhendo 17,25 milhões de toneladas da fruta em 2016, o equivalente a $21 \%$ do total produzido no mundo (FAO, 2018). O estado de São Paulo é o maior estado produtor de laranja do País, sendo conhecido como o cinturão citrícola brasileiro. Segundo o IBGE (2018), este estado produziu 14,3 milhões de toneladas de laranja em 2017, o equivalente a quase $77 \%$ da produção nacional.

Além da grande representatividade mundial e nacional, a citricultura também é importante para a economia, principalmente paulista. Segundo noticiado na imprensa, entre janeiro e agosto de 2016, a citricultura foi a principal atividade da agropecuária paulista a criar empregos no estado (Canal Rural, 2016), mesmo diante da crise econômica.

Uma parte dos empregos e da importância ao estado paulista tem origem na industrialização da fruta. Desde o nascimento da citricultura no estado de São Paulo, ela possui como característica a presença de processadoras 
de suco de laranja (Ito \& Zylberstajn, 2014; Paulillo \& Neves, 2015), com grande proporção de fruta destinada a este segmento - cerca de $80 \%$ da produção paulista (Ito \& Zylberstajn, 2014).

Desde a década de 1980, o Brasil se consolidou como maior e mais competitivo produtor mundial de suco de laranja concentrado e congelado (Costa et al., 2012). Segundo o Departamento de Agricultura dos Estados Unidos (USDA, 2018), o Brasil respondeu em $2016 / 17$ por $68 \%$ da produção mundial de suco de laranja e 78,5\% das exportações globais da commodity. A receita com as exportações de suco de laranja do Brasil somou, em 2017, US\$ 1,94 bilhão (ComexStat, 2018).

Apesar da importância da citricultura no estado de São Paulo e no Brasil, a cultura da laranja vem perdendo representatividade nos últimos anos. Segundo o Instituto Brasileiro de Geografia e Estatística (IBGE, 2018), de 2011 para 2017, mais de 130 mil hectares de laranja foram eliminados do estado de São Paulo, uma queda de mais de $23 \%$ na área plantada com a cultura neste período, mas de apenas $6,5 \%$ na produção da fruta. Vale lembrar que apesar da redução no cultivo, o reflexo na produção foi menor principalmente devido ao adensamento dos pomares e do ganho em tecnologia, fatores que têm permitido melhor produtividade. O principal motivo para a forte retração na área com laranja no estado foi o mais recente período de "crise" na citricultura, que resultou na saída de muitos produtores da atividade (Carrer \& SouzaFilho, 2016). Nas safras 2012/13 e 2013/14, as indústrias paulistas acumularam elevados volumes de suco em estoque (CitrusBr, 2018), reduzindo sua necessidade de matéria-prima. Assim, os preços pagos aos citricultores ficaram em patamares bastante baixos - entre $\mathrm{R} \$ 6,00 \mathrm{e}$ $\mathrm{R} \$ 8,00 /$ caixa de $40,8 \mathrm{~kg}$, colhida e posta na processadora (HF BRASIL, 2018) - resultando em abandono da atividade para alguns. Nos anos subsequentes, contudo, os preços se recuperaram, como reflexo da redução dos estoques de passagem.

\section{O perfil do produtor e da indústria processadora de suco}

A citricultura paulista é caracterizada por um grande número de pequenas propriedades, e um pequeno número de grandes áreas. Segundo dados da Coordenadoria de Defesa Agropecuária do estado de São Paulo (CDA, 2016) referentes ao primeiro semestre de 2016, haviam 10.320 propriedades com citros no estado, sendo que apenas 3\% delas possuía mais de 100 mil plantas na propriedade. Por outro lado, estas poucas propriedades ( $3 \%$, ou 325 fazendas) respondiam por quase $60 \%$ da quantidade total de plantas cítricas do estado de São Paulo. Assim, apesar de poucas fazendas grandes, elas são as mais representativas no total da citricultura paulista.

Este cenário acentua as dificuldades enfrentadas pelo pequeno citricultor, já que está inserido em um mercado onde há concentração tanto do lado da oferta (poucos produtores de maior porte com a maior parte da produção) quanto do lado da demanda (poucas grandes empresas compradoras de laranja). Ainda assim, a concentração industrial é mais acentuada que a produção agrícola (Ito \& Zylbersztajn, 2016). Inclusive, muitas destas grandes propriedades são pertencentes às grandes indústrias, já que há alguns anos as empresas adotaram como estratégia a integração vertical, com processadoras aumentando a produção própria de laranja (Ito \& Zylberstajn, 2014). Assim, os pomares não pertencentes à indústria são chamados de "citricultura independente", e em muitos casos têm dificuldades na comercialização da laranja (Paulillo \& Neves, 2015).

As indústrias de processamento de frutas cítricas, no geral, são de grande porte, já que a atividade de produção de suco depende de economias de escala (Ito \& Zylbersztajn, 2016). No geral, elas concentram todo o processo (recebimento da fruta, processamento, estocagem e comercialização), e geralmente não produzem outros sucos, sendo um investimento bastante específico (Ito \& Zylberstajn, 2014).

Uma característica da indústria de suco de laranja, que tem se acentuado cada vez mais, é o grau de concentração, com a maior parte da produção em poucas empresas. Em 1975, por exemplo, cinco empresas respondiam por $75 \%$ da produção nacional de suco de laranja, chegando ao ápice em 1985, quando quatro empresas detinham mais de $90 \%$ deste mercado - a concentração diminuiu um pouco em 1999, com três empresas respondendo por $75 \%$ do mercado (Paulillo, 1999). Em 2015, contudo, o ápice de 1985 foi ultrapassado, com apenas três empresas (Citrosuco, Cutrale e Louis Dreyfus Commodities) detentoras de 90\% do mercado de suco de laranja (Neves \& Kalaki, 2015).

A concentração da indústria paulista de suco de laranja gerou conflitos no que diz respeito a negociações de preços entre comprador e fornecedor, já que passou a haver uma assimetria de forças favorável à indústria (Clemente \& Coelho, 2013; Figueiredo et al., 2013). As processadoras, portanto, passaram a ter condições para exercer poder de mercado (Ito \& Zylberstajn, 2014). 
Mundialmente, o mercado de suco de laranja pode ser caracterizado como uma competição imperfeita, já que são poucos os países envolvidos na produção e exportação de suco de laranja (Costa et al., 2012). Assim, a citricultura paulista pode ser caracterizada, ao mesmo tempo, como um oligopólio (poucos exportadores de suco) (Paulillo, 1999) e como um oligopsônio (poucos compradores de fruta e milhares de vendedores) (Paulillo, 2006).

Existe, contudo, um número considerável de pequenas processadoras de suco no estado de São Paulo. Apesar de não haverem referências quantificando-as, informações de agentes do setor indicam que poderiam haver mais de 15 pequenas unidades industriais em 2017, porém a representatividade das mesmas ainda é pequena diante da capacidade instalada das três grandes processadoras de suco.

\section{Oligopólio e a indústria paulista de suco de laranja}

O oligopólio é um mercado de competição imperfeita, com elevada concentração do lado da oferta (Farina, 2000). Ele é caracterizado por um pequeno número de empresas produtoras, que competem umas com as outras objetivando maximizar seus lucros e/ou aumentar a sua participação no mercado (Shapiro, 1989; Zhang et al., 2017). Segundo Sauaia \& Kállas (2007), as empresas dentro de um oligopólio possuem duas opções: competir entre si para tentar aumentar a sua participação no mercado ou cooperar umas com as outras, para que todas tenham lucros considerados aceitáveis.

As empresas pertencentes a este mercado determinam preço e volume em função dos concorrentes (Sauaia \& Kállas, 2007), sendo menos influenciadas pela demanda global (Lima, 1985). No que diz respeito à formação de preços, possui algumas características fortes do monopólio, ao mesmo tempo em que tem algumas limitações da competição (Lima, 1985). Segundo Farina (2000), contudo, capacidade de definir os preços através do controle da oferta depende das barreiras à entrada de novas firmas e da coordenação entre as empresas do oligopólio.

O sistema agroindustrial de suco de laranja, pelo menos até meados de 2012, poderia ser caracterizado como um oligopólio concentrado (Farina, 2000), já que era formado por poucas empresas, diz respeito a um produto homogêneo (commodity) e com barreiras técnicas à entrada. Contudo, a partir de 2012, com o nascimento de muitas pequenas firmas, há dúvidas se este poderia ser considerado como um oligopólio competitivo, onde se mantém a elevada concentração, porém conta-se com muitas firmas médias e pequenas (no caso do sistema agroindustrial citrícola, pequenas) formando uma franja competitiva (Farina, 2000).

Um oligopólio competitivo possui poucas grandes empresas (no caso do sistema agroindustrial de suco de laranja, três) com domínio do mercado, restando às outras indústrias menores trabalharem na franja (Pereira \& Bánkuti, 2016). Estas firmas pequenas não teriam acesso aos principais segmentos de mercado, dependendo de mercados marginais (Farina, 2000).

\section{MATERIAL E MÉTODO}

Pela pesquisa ter como enfoque avaliar a percepção de citricultores sobre a indústria paulista de suco de laranja, optou-se pela abordagem de pesquisa qualitativa do tipo descritiva (Gray, 2012), já que opiniões e suas justificativas são relatadas, bem como as influências das indústrias no setor produtivo.

A abordagem qualitativa mostrou-se a mais adequada, já que permite maior liberdade na aplicação e inclusive considera o surgimento de ideias e hipóteses emergentes, diferente da abordagem quantitativa (Gray, 2012; Sampieri et al., 2013). Já a análise descritiva, segundo Gray (2012), tem como objetivo analisar as características de uma população, podendo ser em um determinado momento (no caso desta pesquisa), ou comparativamente ao longo do tempo.

Os dados foram coletados através de uma entrevista semiestruturada (Cooper \& Schindler, 2011; Gray, 2012; Flick, 2013; Sampieri et al., 2013). O guia de entrevistas é uma forma de orientar o entrevistador, porém com liberdade na inclusão de questões que possam contribuir ou estimular o entrevistado (Flick, 2013; Barbot, 2015). A entrevista foi escolhida como método de coleta de dados devido ao caráter exploratório da pesquisa, buscando captar a visão de cada indivíduo (Flick, 2013). Foi feito um pré-teste (Gray, 2012), que gerou adaptações no roteiro. Após a adequação aos propósitos da pesquisa, as entrevistas foram realizadas por telefone (Gray, 2012; Cooper \& Schindler, 2011) no período de 31 de outubro a 18 de novembro de 2016. O roteiro utilizado está disponível no apêndice. Todos os entrevistados foram informados do propósito da pesquisa (Cooper \& Schindler, 2011), que seria gravada, e consentiram em participar. Segundo Barbot (2015), o pesquisador precisa ter o consentimento 
do entrevistado, e a gravação da entrevista, na maioria dos casos, é indispensável. Após a gravação, as entrevistas foram transcritas, para permitir uma leitura flutuante.

Os sujeitos de pesquisa são dez produtores de laranja no estado de São Paulo, que forneçam pelo menos uma parte de sua produção para a indústria e com pelo menos cinco anos de atuação citrícola. Apesar do número de entrevistados não ser significativo diante do total da população, serve para o propósito do estudo, que possui caráter qualitativo, não havendo intenção de generalização. O tempo de atuação é importante, já que sinaliza que o citricultor já possui um mínimo de contato com este setor, e inclusive já passou por períodos de altas e baixas nos preços. O produtor de laranja foi o alvo da pesquisa devido à relação destes com a indústria de suco de laranja, muitas vezes considerada conflituosa (Ito \& Zylbersztajn, 2014; Ito \& Zylberstajn, 2016). Em média, o grupo pesquisado destina $57,75 \%$ de sua produção à indústria, com variação de $10 \%$ a $100 \%$ de sua produção anual. Devido à importância de determinados critérios na pesquisa, os entrevistados foram escolhidos com base em amostragem não probabilística por critérios, também chamada de amostragem por julgamento (Cooper \& Schindler, 2011; Gray, 2012 adaptado de Patton, 2002; Berg, 2007). Neste tipo de amostragem os selecionados devem atender a alguns critérios. No caso da pesquisa, todos os selecionados são citricultores há mais de cinco anos e com fornecimento de pelo menos parte de sua produção para a indústria.

A estratégia de investigação utilizada para compreender a percepção dos entrevistados foi a análise de conteúdo (Bardin, 1979; Bauer, 2012). Segundo Bardin (1979, p.37), a análise de conteúdo é

[...] um conjunto de técnicas de análise das comunicações visando obter, por procedimentos sistemáticos e objetivos de descrição do conteúdo das mensagens, indicadores que permitam a inferência de conhecimentos relativos às condições de produção/recepção destas mensagens.

Segundo Bardin (1979) e Bauer (2012), ela permite a redução da complexidade de uma coleção de textos, e produz inferências de um texto para o seu contexto social. A análise de conteúdo é rica por permitir desviar o olhar para uma outra significação da mensagem, sem ser uma leitura ao pé da letra (Bardin, 1979; Bauer, 2012). O procedimento de análise foi realizado através do processo de categorização (Bardin, 1979; Bauer, 2012), onde os principais temas da entrevista são divididos em categorias para posterior análise. É importante lembrar que as discussões levantadas nas categorias fazem parte das opiniões particulares dos entrevistados, não refletindo a opinião das autoras.

\section{RESULTADOS E DISCUSSÃO}

Para a elaboração da análise de conteúdo, foi utilizada a categorização como forma de identificar os principais blocos de opiniões dos entrevistados com relação à indústria, tanto as grandes quanto as pequenas. As categorias definidas foram: a grande indústria como solução de problemas, a grande indústria como causa de problemas, a concentração industrial que influencia nos resultados do produtor, pequena indústria: opção diante da falta de opções, e diversificação como estratégia de menor dependência.

\section{Categoria 1: A grande indústria como solução de problemas}

A Categoria 1 revelou uma percepção geral dos produtores com relação à indústria: independentemente de suas características, e mesmo diante dos conflitos existentes entre produtor e indústria, é consenso entre os produtores a importância das processadoras de suco de laranja para o desenvolvimento da citricultura no estado de São Paulo, sendo uma solução para o escoamento de toda a produção do estado. O fato de cerca de $80 \%$ da produção de laranja paulista ser destinada a este segmento (Ito \& Zylberstajn, 2014) confirma a importância deste elo de comercialização. O Entrevistado 3 considera a atividade citrícola inviável sem a indústria (considerando a atual extensão da atividade), já que o mercado de fruta in natura não absorveria todo o volume produzido no estado. Inclusive, o Entrevistado 10 considera que é devido às indústrias que a citricultura é tão representativa hoje. O desenvolvimento do polo produtor de laranja no estado de São Paulo foi impulsionado pelo desenvolvimento das indústrias, e este canal de comercialização domina o estado de São Paulo desde os anos 60 (Paulillo \& Neves, 2015). Assim, a indústria foi definida pelo Entrevistado 9 como um mal necessário, sendo para os Entrevistados 2 e 3 "ruim com elas, pior sem elas".

Mesmo para os produtores que possuem prioridade no fornecimento de laranja para o mercado de fruta in natura, a indústria também se mostra como determinante 
para o desempenho da atividade. Segundo Paulillo \& Neves (2015), a produção voltada para o mercado de fruta in natura é mais exigente com relação ao manejo do que a laranja voltada para a industrialização. Como pontuou o Entrevistado 6, mesmo conduzindo o pomar para a produção de laranjas com a qualidade exigida pelo mercado de mesa, pelo menos um percentual mínimo acaba com características inferiores ao padrão exigido; seja por condições climáticas ou por deficiência no desenvolvimento da planta. Assim, estes citricultores também possuem relações comerciais com a indústria, e obrigatoriamente destinam pelo menos uma parte de sua colheita para a produção de suco de laranja. Segundo o Entrevistado 8, portanto, a manutenção de relações comerciais com a indústria é um ponto estratégico para os produtores de laranja para comercialização in natura.

Outro fator também relatado por produtores entrevistados é que o comportamento da indústria também exerce influência no cenário de preços no mercado in natura. Conforme o Entrevistado 6, o mercado de laranja de mesa reflete o cenário de preços e demanda industrial, confirmado por análise dos dados da HF Brasil (HF Brasil, 2018), onde os preços registram movimentos de alta e de baixa semelhantes. Assim, a independência completa da indústria, mesmo para aqueles que não comercializam prioritariamente neste segmento, mostra-se praticamente impossível na citricultura paulista.

Por fim, as grandes indústrias foram vistas como "solução de problemas" também no sentido de terem forte poder de barganha no mercado externo. Segundo o Entrevistado 9, as grandes indústrias são boas negociadoras e possuem visão do mercado externo. Neste cenário, elas possuem credibilidade e são "boas pagadoras", não havendo problemas de inadimplências ou atraso nos pagamentos.

\section{Categoria 2: A grande indústria como causa de problemas}

A categoria 2 é uma visão quase que contrária à categoria 1, permitindo concluir que, para o citricultor, a grande indústria é tanto solução quanto causa de problemas. Na maioria dos casos, o mesmo entrevistado tem as duas visões da grande indústria paulista, reconhecendo a sua importância para o setor, mas também destacando seus pontos negativos e limitações.

Um dos grandes motivos pelo qual a indústria é vista como causa de problemas aos citricultores é a estratégia de integração vertical para trás adotada pelas processadoras.
Segundo o Entrevistado 1, elas estão cada vez mais plantando laranja, aumentando a participação das laranjas próprias no total da citricultura paulista. Barbosa \& Gitahy (2016), Ito \& Zylberstajn (2014) e Figueiredo et al. (2013) comentam que as indústrias buscaram proteger seus investimentos por meio da integração vertical para trás, intensificando a produção própria de laranja. Esta medida visa diminuir a dependência de produtores (Barbosa \& Gitahy, 2016), garantindo parte do abastecimento de matéria-prima. Segundo Williamson (1979), em períodos de incerteza, aumenta o benefício da integração vertical. Na citricultura, isso pode ser verificado em anos de baixa oferta, como em 2016: o fato de a indústria possuir pelo menos parte da matéria-prima já garantida em seus pomares próprios permite maior conforto nas negociações.

A busca das processadoras por garantir parte de sua necessidade de matéria-prima também resulta no tratamento diferenciado aos grandes produtores, segundo os Entrevistados 7 e 10. Mello \& Paulillo (2010) confirmam esta postura das processadoras, e relatam ser interessante para elas ter o grande produtor como fornecedor exclusivo, devido à necessidade de regularidade no suprimento de suco de laranja e também para minimizar a ociosidade das fábricas, beneficiando-se de economias de escala. A laranja do pequeno e do médio produtor, portanto, seria considerada um complemento ao volume programado de processamento.

Além do tratamento diferenciado dado aos grandes produtores, outro comportamento reprovado pelos entrevistados é a postura da indústria no que diz respeito à precificação e contratos. Inclusive, as grandes processadoras foram apontadas pelo Entrevistado 2 como "culpadas" pela saída de muitos produtores da atividade, já que pagaram preços abaixo do custo de produção da fruta em anos recentes. Essa diminuição no número de propriedades com citros é confirmada pelos dados da Coordenadoria de Defesa Agropecuária (CDA, 2016), que indica que a citricultura perdeu mais de 7.500 propriedades do primeiro semestre de 2012 para o primeiro semestre de 2016, o equivalente a $42 \%$ das propriedades existentes em 2012 - que foi justamente o ano em que os preços ficaram em patamares bastante baixos (HF Brasil, 2018).

Os contratos de médio e longo prazo, mesmo tendo preços pré-definidos, também são fonte de conflitos. O Entrevistado 4 possui contrato de longo prazo com a indústria, e relatou que, em anos em que os preços dos contratos são considerados mais altos do que os preços praticados pelo mercado, a processadora "obriga" os produtores a aceitar uma redução nos valores. Contudo, 
quando o oposto ocorre (o contrato fica inferior ao patamar de mercado, como em 2016), as indústrias não permitem renegociação. Ito \& Zylbersztajn (2016) relatam que o setor brasileiro de suco de laranja utiliza os contratos como veículo de poder econômico, já que os outros agentes (produtores) não podem influenciar no processo de seleção de termos. Inclusive, as processadoras já foram acusadas de usá-los para aumentar os lucros deliberadamente (Ito \& Zylbersztajn, 2016).

Figueiredo et al. (2013) fizeram um estudo com o objetivo de examinar se havia uso de poder de mercado por parte das indústrias de suco de laranja em suas transações com citricultores. Através da análise das margens brutas de comercialização e da transmissão de preços, os autores concluíram que havia indícios do uso de poder de mercado por parte das indústrias. O Entrevistado 8, contudo, levanta uma questão bastante polêmica, e alega que provavelmente os citricultores fariam o mesmo se estivessem no lugar das indústrias - ou seja, buscariam beneficiar-se o máximo possível de suas negociações em caso de maior poder de mercado.

Por último, um comportamento esporádico das indústrias levantado pelo Entrevistado 2 foi a programação da colheita; segundo ele, a indústria define a data que o citricultor deve entregar, sem grandes preocupações com relação à maturação da fruta. Muitas vezes, a laranja já estava "no ponto", mas a quantidade recebida pelas empresas era limitada. Neste cenário, citricultores têm dificuldade na programação dos trabalhos de campo, já que a estrutura de mão de obra muitas vezes tornaria possível a colheita e transporte de maiores volumes, que são barrados pela indústria. Ito \& Zylbersztajn (2016) também abordam esse tema, e comentam que muitos citricultores consideram que esta tentativa de atraso pode ser proposital, já que causaria desidratação da fruta - o que resultaria em menor peso (e consequentemente, menor pagamento) e em maior concentração de sólidos solúveis (benéfico para as indústrias, já que melhora o rendimento da produção de suco de laranja).

\section{Categoria 3: A concentração industrial que influencia nos resultados do produtor}

A indústria de suco de laranja paulista apresenta um elevado poder de mercado, já que apresenta uma estrutura concentrada na distribuição global do suco de laranja (oligopólio), bem como na compra da matéria-prima (oligopsônio). Produtores entrevistados consideram que a concentração industrial no sistema agroindustrial citrícola tem influência direta em seu negócio, com reflexos negativos. Os principais pontos levantados foram a falta de concorrência, pelo fato de existirem apenas três opções de comercialização, aumentando significativamente a dependência do produtor e o poder de mercado das indústrias. Segundo o Entrevistado 8, o risco da atividade seria menor caso houvessem mais opções de comercialização, com uma concorrência maior, inclusive com chance de melhor remuneração. Essa concentração, por sua vez, é justificada pelo Entrevistado 1 pela exigência de grande escala de produção, confirmada por Ito \& Zylbersztajn (2016) como essencial para o bom desempenho da indústria de suco de laranja.

Contudo, não é de hoje que o sistema agroindustrial citrícola é concentrado. Paulillo (1999), com base em dados do Instituto de Economia Agrícola (IEA), fez uma análise quinquenal da concentração industrial citrícola de 1970 a 1995, e constatou que o nível mínimo de concentração foi em 1975, quando cinco empresas respondiam por $75 \%$ da capacidade instalada. Estas poucas empresas disponíveis, por sua vez, são inclusive acusadas pelo Entrevistado 1 de serem cartelizadas. A formação de cartel seria um acordo entre concorrentes com objetivo de fixar preços ou cotas de produção, dividindo clientes e mercados de atuação, eliminando a concorrência (Silva \& Ralha, 2010). A formação de cartel, segundo Sauaia \& Kállas (2007), é uma ação de cooperação considerada ilegal, e é investigada pelo Conselho Administrativo de Defesa Econômica (Cade) (Silva \& Ralha, 2010).

No caso da laranja, a formação de cartel teria ocorrido através de acordos para a compra de matéria-prima, usando contratos a termo para aumentar os lucros deliberadamente (Ito \& Zylbersztajn, 2016). O processo de investigação estava em trâmite no Cade até novembro de 2016, quando foi noticiado pelo Conselho a homologação da investigação, com as indústrias acusadas, juntamente com nove pessoas físicas, devendo recolher, no total, R \$ 301 milhões como contribuição pecuniária, valor mais alto já pago em acordos junto ao Cade (2016). Assim, as acusações de produtores, ao que tudo indica, não seriam infundadas; as indústrias paulistas, em algum momento de sua história, já abusaram de seu poder de mercado, inclusive através de práticas ilegais de cooperação. Vale lembrar, contudo, que os competidores do oligopólio podem usar da comunicação como meio de lidar com a limitação de informações de mercado, o que não significa descumprir as leis (Sauaia \& Kállas, 2007). 
A concentração como poder de mercado, por sua vez, foi apontada pelo Entrevistado 4 como efetiva nos anos em que há excedente de suco de laranja em estoque. No ano de 2016, quando a oferta foi bastante restrita (Fundecitrus, 2018), nem mesmo a estrutura concentrada foi suficiente para eliminar a disputa por matéria-prima entre as grandes processadoras.

O oligopólio no sistema agroindustrial citrícola, contudo, pode ter também um lado positivo, como apontado pelo Entrevistado 1:

Entrevistado 1: Eu acho negativo (o oligopólio), porque você reduz a concorrência. [...] Ele tem um aspecto unicamente positivo que eu vejo é que são indústrias fortes, economicamente sólidas.

A concentração e organização industrial, portanto, é vista como positiva do ponto de vista da solidez deste mercado. As processadoras de suco de laranja são conhecidas pela sua força e credibilidade, inclusive este é um parâmetro que ainda limita a adesão às pequenas indústrias - que serão abordadas na próxima categoria. Segundo Barney \& Hesterly (1998), organizações de maior porte são consideradas menos suscetíveis ao fracasso, sendo o tamanho um indicador de um futuro confiável.

\section{Categoria 4: Pequena indústria: opção diante da falta de opções}

A citricultura sempre teve como característica a presença de pequenas indústrias de suco de laranja. Apesar de não haverem referências com relação ao seu número, fontes do setor indicam que, em 2016, cerca de 15 pequenas indústrias estavam instaladas no estado de São Paulo, aumentando em número principalmente a partir de 2012, com a crise vivenciada pelo setor produtivo. Naquele período, os preços oferecidos pela indústria foram bastante baixos (HF Brasil, 2018), além de haver grande sobra de fruta no mercado. Este cenário levou muitos citricultores a optarem por abrir uma indústria como opção de escoamento de suas próprias frutas. Segundo Barney \& Hesterly (1998), mudanças ambientais criam oportunidades para novas organizações entrarem, justamente o que ocorreu com a citricultura. Esta ação, de produtores abrindo indústria para o processamento de sua matéria-prima, é chamada de integração vertical para frente (Ito \& Zylbersztajn, 2014).

No geral, o surgimento destas pequenas empresas é visto com bons olhos pelos citricultores, já que aumentaria o número de compradores de matéria-prima e auxiliaria no escoamento da laranja. Para o Entrevistado 5, quanto mais indústrias existirem, melhor, mas no geral, não consideram que estas pequenas possam virar grandes um dia, como pontuado pelo Entrevistado 7:

Entrevistado 7: Não que elas vão virar grandes, mas elas vão se fortalecer, vão dar um trabalhinho aí.

Apesar de serem consideradas como opções, a categoria 4 revela alguns pontos críticos apontados por citricultores com relação às pequenas indústrias do estado de São Paulo. O título da categoria, já ilustra o primeiro ponto crítico: no geral, elas são consideradas como opção diante da falta de opções. Como citado pelo Entrevistado 9, elas são procuradas, na maioria das vezes, quando não se tem alternativa de escoamento junto às grandes indústrias. Assim, dificilmente são consideradas como primeira escolha dos citricultores para a comercialização da laranja. Alguns casos, contudo, vão na contramão, como o do Entrevistado 8, que optou por negociar com a pequena indústria como forma de depender menos das grandes processadoras. Um benefício apontado por ele é que, na pequena indústria, o produtor negocia diretamente com os donos, com as pessoas que realmente possuem poder de decisão dentro da empresa.

O segundo ponto crítico apontado pelo Entrevistado 10 é que todos sabem que existem pequenas indústrias no estado de São Paulo, mas poucos realmente sabem quantas elas são, sua localização e suas condições de comercialização. A maioria conhece ou teve contato com uma ou outra, mas não há um mapeamento dos nomes e localização destas empresas. O motivo pode ser tanto por serem novas neste setor quanto por serem pouco representativas, um segundo ponto crítico que também emergiu durante as entrevistas. $\mathrm{O}$ entrevistado 8 relatou que as pequenas empresas ajudam, mas fazem um trabalho considerado marginal, sem grande representatividade. De fato, em oligopólios competitivos (o que pode ser o caso do sistema agroindustrial citrícola), as grandes empresas dominam o mercado, enquanto as menores trabalham na franja, dependendo de mercados marginais (Pereira \& Bánkuti, 2016; Farina, 2000).

Indo de encontro a esta característica, foi apontado como crítica a suscetibilidade destas empresas no sistema agroindustrial citrícola. O Entrevistado 1, bastante antigo na citricultura, acompanhou o surgimento e o desaparecimento de muitas pequenas empresas, sendo que a maioria delas terminou pouco rentável aos seus proprietários. Outras conseguiram ter certa consolidação 
no mercado a ponto de "incomodar" as grandes indústrias - e foram compradas por elas.

Entrevistado 1: Algumas pequenas indústrias estão fazendo um pouco de barulho, mas isto de uma hora para outra vai sumir, [...] os grandes vão engolir.

Este histórico também reflete na credibilidade das pequenas empresas. Um ponto levantado pela maioria dos entrevistados é o maior risco destas indústrias com relação a pagamento, já que não oferecem a mesma segurança de recebimento que as grandes indústrias. Portanto, em anos de elevada demanda industrial por matéria-prima, as pequenas indústrias precisam pagar valores acima das grandes processadoras para que sejam atrativas aos produtores diante deste ponto considerado crítico. Esta necessidade, contudo, tende a aumentar os custos para a produção do suco de laranja, dificultando a sua competitividade.

Um ponto apontado também é com relação ao ramo de atuação destas pequenas empresas. Segundo o Entrevistado 8, aquelas que optam por comercializar o suco concentrado no mercado externo devem ter dificuldades, já que este é o mesmo mercado das grandes indústrias. Uma opção apontada pelo entrevistado é a produção de suco integral para venda no mercado brasileiro, já adotado por algumas destas pequenas indústrias, que é um ramo diferente das grandes processadoras - inclusive, incentivaria o aumento do consumo nacional. Barney \& Hesterly (1998) comentam que, de acordo com o modelo de particionamento de recursos, as pequenas organizações, quando atuam em mercados concentrados, podem explorar mercados sem competição com as empresas maiores como forma de se manterem competitivas no mercado.

Um dos entrevistados, pensando nas pequenas indústrias como exploradoras do mercado nacional de suco de laranja, concluiu:

Entrevistado 6: se tivesse uma escala maior, eu mesmo montaria uma pequena indústria.

Um contraponto com as indústrias grandes, que priorizam negociar com grandes produtores (Mello \& Paulillo, 2010), foi sugerido pelo Entrevistado 10: que as pequenas indústrias fossem uma opção de escoamento para os pequenos produtores, já que estes, em muitos casos, são os que mais possuem dificuldade na comercialização de sua laranja. Assim, a pequena indústria poderia explorar as possibilidades de parceria com citricultores de pequeno porte.

\section{Categoria 5: Diversificação como estratégia de menor dependência}

Apesar de a indústria ser o canal de distribuição preferido do citricultor (Mello \& Paulillo, 2010), o fato de o sistema agroindustrial citrícola ser concentrado faz com que muitos produtores busquem diminuir sua dependência das grandes indústrias. O Entrevistado 9, por exemplo, não tem a indústria como principal forma de comercialização da laranja, e apontou que os produtores que dependem exclusivamente da indústria talvez tenham uma situação mais delicada dentro da atividade citrícola, sendo mais impactados em períodos de elevada oferta.

A diversificação é vista como uma opção, tanto de culturas quanto de formas de comercialização da laranja. Para Paulillo \& Neves (2015), os produtores que desejam continuar na atividade citrícola têm como opção o mercado de laranja in natura, que exige um manejo do pomar diferenciado da indústria, sendo a qualidade um fator favorável à obtenção de preços melhores. O Entrevistado 7 concorda com a afirmação, destacando que o mercado de mesa pode ser uma boa opção para os que possuem qualidade, e acrescenta que a localização da produção também pode influenciar na boa colocação neste canal de comercialização, já que algumas regiões possuem características mais apreciadas por este segmento devido às condições climáticas. Para o Entrevistado 1, esta pode ser uma boa opção de agregação de valor para pequenos produtores:

Entrevistado 1: os pequenos produtores que eu conheço estão se direcionando para mesa, para laranja de mesa bem cuidada, porque eles acham que ai eles podem ter uma agregação de valor que permite cuidar.

O mercado de fruta in natura se mostra como boa opção, segundo o Entrevistado 4, por não haver necessidade de pagamento de frete - este custo é pago pelo comprador. Para Mello \& Paulillo (2010), além do fator frete, o mercado de laranja de mesa é um canal alternativo à indústria, possuindo como vantagens ao produtor a falta de barreiras de escala, os maiores preços, que são negociados no momento da venda (ou seja, acompanham as variações do mercado), a liberdade de conquistar novos compradores (já que a venda não é exclusiva, como em muitos casos ocorre na indústria), dentre outras.

Dentro da comercialização da laranja in natura, algumas opções foram apresentadas: o Entrevistado 3, por exemplo, sugeriu embalar as laranjas, distribuindo nas feiras e no 
varejo, além de usar a internet para a comercialização da fruta-posicionamento já adotado pelo website "laranjas online" (Laranjas online, 2016), por exemplo.

\section{CONCLUSÕES}

Para o citricultor, a indústria de suco de laranja pode ser considerada tanto parceira quanto fonte de conflitos. Ela é considerada totalmente essencial para a citricultura paulista, considerando a dimensão atual de produção da fruta e a absorção limitada do segmento in natura. Inclusive para os produtores que comercializam a maior parte de sua produção no mercado de fruta de mesa, a indústria é vista como essencial, já que nem toda a laranja costuma ter a qualidade exigida pelo mercado in natura, e a única opção de venda acaba sendo a indústria.

O fato de o setor industrial de suco de laranja ser bastante concentrado, com apenas três grandes empresas dominando a maior parte do mercado, é uma característica vista como negativa, já que reduz as opções de comercialização ao produtor. Isso, inclusive, é um dos fatores que torna a relação entre o produtor e a grande processadora conflituosa. A concentração do sistema agroindustrial de laranja, inclusive, foi relatada como afetando a rentabilidade dos produtores, já que, com mais empresas compradoras de laranja, a disputa por matéria-prima poderia ser maior, resultando em melhor remuneração ao citricultor.

As pequenas processadoras, por sua vez, ainda são pouco conhecidas entre os produtores, que sabem da existência de poucas delas. Além do desconhecimento de boa parte das pequenas, a aceitação do produtor com relação à comercialização com estas empresas ainda possui restrições. Algumas pequenas firmas são relatadas como tendo reputação negativa por conta de atrasos em pagamentos, o que não acontece quando se comercializa com as grandes. Neste cenário, a pequena indústria é vista como uma opção diante da falta de opções.

Mesmo diante de diversas restrições com relação às pequenas processadoras, no geral, produtores veem com bons olhos o seu surgimento e o aumento da quantidade destas empresas, já que seriam mais opções de comercialização, inclusive para pequenos produtores, muitas vezes deixados de lado pelas grandes fábricas.

Como sugestão para futuros estudos, indica-se realizar um mapeamento das pequenas fábricas do estado de São Paulo, já que alguns entrevistados demonstraram conhecer poucas destas empresas. Além disso, para estas pequenas firmas, mostra-se importante analisar a competitividade, já que a credibilidade das mesmas é um fator limitante para que os produtores optem por negociar mais frequentemente com as mesmas - por enquanto, não são vistas como primeira opção.

Este estudo traz como contribuição a apresentação de como os produtores veem a indústria e a influência da estrutura concentrada das mesmas para o próprio citricultor. Principalmente, a visão destes com relação à pequena indústria se mostra como grande contribuição, já que por ser um segmento emergente na citricultura, ainda não há estudos avaliando a forma com que estas são vistas por seus principais fornecedores de matéria-prima.

Como limitação deste estudo, destaca-se a quantidade e a seleção dos entrevistados, que considerou aptos todos os citricultores que comercializam com a indústria, independente do percentual de produção enviado ao processamento. Um estudo com produtores categorizados por escala de produção e cuja indústria seja o principal destino de comercialização poderia apresentar resultados diferentes ao observados no presente trabalho.

\section{REFERÊNCIAS}

Associação Nacional dos Exportadores de Sucos Cítricos - CITRUSBR (2018). Recuperado em 31 de julho de 2018, de www.citrusbr.com

Barbosa, G. R., \& Gitahy, L. (2016). Pragas e doenças: controvérsias na constituição da cadeia produtiva da laranja no estado de São Paulo dos anos 1930 aos 2000. Desafio Online, 4(2), 41-62.

Barbot, J. (2015) Conduzir uma entrevista face a face. In Paugam, S. (Coord). A pesquisa sociológica (pp. 102123). Vozes: Petrópolis.

Bardin, L. (1979) Análise de conteúdo. (223 pp.). Lisboa: Edições.

Barney, J. B., \& Hesterly, W. (1998) Economia das organizações: entendendo a relação entre as organizações e a análise econômica. In SR Clegg, C Hardy, WR Nord. Handbook de estudos organizacionais: modelos de análises e novas questões em estudos organizacionais (Vol. 3, pp. 131-172). São Paulo: Atlas.

Bauer, M. W. (2012) Análise de conteúdo clássica: uma revisão. In Bauer, MW, Gaskell, G. Pesquisa Qualitativa com texto, imagem e som: um manual prático (p. 189217). Vozes, Petrópolis. 
Berg, B. L. (2007) Qualitative research methods for the social sciences (448 p). Boston: Pearson.

Canal Rural (2016) Citricultura é setor do agro que mais emprega em São Paulo. Recuperado em 31 de julho de 2018, de http://www.canalrural.com.br/noticias/agricultura/ citricultura-setor-agro-que-mais-emprega-sao-paulo-64432

Carrer, M. J., \& Souza-Filho, H. M. (2016) Economias de escala e eficiência econômica na produção de laranja no estado de São Paulo. Revista de Economia e Sociologia Rural, 54(1), 51-70.

Clemente, F., \& Coelho, A. B. (2013) Viabilidade de implantação de contratos futuros de suco de laranja concentrado congelado no Brasil. Pesquisa \& Debate, 24(2), 221-242.

ComexStat (2018) Sistema para consultas do Ministério da Indústria, Comércio Exterior e Serviços. Recuperado em 31 de agosto de 2018, de http://comexstat.mdic.gov.br

Conselho Administrativo de Defesa Econômica-CADE (2016). Cade celebra acordos em investigação de cartel de compras de laranja. Recuperado em 31 de julho de 2018, de http://www.cade.gov.br/cade-celebra-acordosem-investigacao-de-cartel-de-compra-de-laranjas

Cooper, D. R., \& Schindler, P. S. (2011) Métodos de Pesquisa em Administração (695 pp). Porto Alegre: Bookman.

Coordenadoria de Defesa Agropecuária do Estado de São Paulo-CDA (2016) Recuperado em 22 de novembro de 2016, de http://www.defesa.agricultura.sp.gov.br/

Costa, C. K. F., Maia, S. F., \& Sampaio, L. M. B. (2012) Exportações brasileiras de suco de laranja e subsídios americanos: uma análise empírica de estratégias comerciais (1991-2006). Revista de Economia e Sociologia Rural, 50 (1), 83-106.

Farina, E. M. M. Q. (2000) Organização industrial no agribusiness. In D. Zylbersztajn, \& M. F. Neves (Org.), Economia e gestão dos negócios agroalimentares (pp. 39-59). São Paulo: Pioneira.

Figueiredo, A. M., Souza-Filho, H. M., \& Paullilo, L. F. O. (2013) Análise das margens e transmissão de preços no sistema agroindustrial do suco de laranja no Brasil. Revista de Economia e Sociologia Rural, 51(2), 331-350.

Flick, U. (2013). Introdução à metodologia de pesquisa: um guia para iniciantes (256 pp.). Porto Alegre: Penso.
Food and Agriculture Organization of the United Nations - FAO. Recuperado em 31 de julho de 2018, de http:// www.fao.org/faostat/en/\#home

Fundo de Defesa da Citricultura - Fundecitrus (2018). Recuperado em 31 de julho de 2018, de http://www. fundecitrus.com.br/

Gray, D. E. (2012) Pesquisa no mundo real (488 pp). Porto Alegre: Penso.

HF Brasil (2018) Recuperado em 31 de julho de 2018, de http://www.hfbrasil.org.br

Instituto Brasileiro de Geografia e Estatística - IBGE. Recuperado em 31 de julho de 2018, de http://www. sidra.ibge.gov.br/

Ito, N. C., \& Zylbersztajn, D. (2014) Incremento da integração vertical parcial no setor citrícola paulista: poder e custos de transação. In Anais XXXVIII Encontro da ANPAD (16 pp.). Rio de Janeiro, RJ: ANPAD.

Ito, N. C., \& Zylbersztajn, D. (2016) Power and selection of contract terms: the case from the Brazilian orange juice sector. Revista de Administração da USP, 51(1), 5-19.

Laranjas online (2016) Recuperado em 31 de julho de 2018, de https://www.laranjasonline.com/

Lima, L. A. O. (1985) Mark-up e determinação de preços no oligopólio - a microempresa em busca de realismo. Revista de Administração de Empresas, 25(2), 29-35.

Mello, F. O. T., \& Paulillo, L. F. O. (2010) Formas plurais de governança no sistema agroindustrial citrícola paulista. Revista de Economia e Sociologia Rural, 48(1), 135-159.

Neves, M. R. F., \& Kalaki, R. B. (2015) Perspectivas para a produção brasileira. Agroanalysis, 35(6), 26-27.

Paulillo, L. F. (1999) Terceirização e reestruturação agroindustrial: avaliando o caso citrícola brasileiro. Revista de Administração Contemporânea, 3(1), 87-103.

Paulillo, L. F. (Coord.) (2006). Agroindústria e citricultura no brasil: diferenças e dominâncias (E-papers, 482 pp.). Rio de Janeiro.

Paulillo, L. F., \& Neves, M. C. (2015) Análise das estruturas de governança de compra de laranja dos maiores packing houses no estado de São Paulo: um estudo multicascos sobre arranjos híbridos. Organizações Rurais \& Agroindustriais, 17(4), 461-478.

Pereira, J. A., \& Bánkuti, S. M. S. (2016) Estrutura de mercado e estratégia: um estudo na indústria brasileira 
de baterias automotivas. Revista Ibero-Americana de Estratégia-RIAE, 15(1), 97-115.

Sampieri, R. H., Collado, C. F., \& Lucio, M. P. B. (2013) Metodologia de pesquisa (28-44 pp.). Porto Alegre: Penso. Sauaia, A. C. A., \& Kállas, D. (2007) O dilema cooperaçăocompetiçăo em mercados concorrenciais: o conflito do oligopólio tratado em um jogo de empresas. Revista de Administração Contemporânea, 11, 77-101.

Shapiro, C. (1989) Theories of oligopoly behavior. In R. Schmalensee, \& R. Willig. Handbook of industrial organization (329-414 pp.). North Holland: Elsevier.

Silva, A. F., Barros, G. S. C., \& Boteon, M. (2017). Price analyses of the Brazilian citrus supply chain. Journal of Food Science and Engineering, 7, 49-58.

Silva, CVS, Ralha, CG (2010) Detecção de cartéis em licitações públicas com agentes de mineração de dados. Revista Eletrônica de Sistemas de Informação, 10(1), 1,19.
United States Department of Agriculture - USDA. (2018). Recuperado em 31 de julho de 2018, de http://apps.fas. usda.gov/psdonline/PSDHome.aspx

Williamson, O. E. (1979) Transaction-cost economics: the governance of contractual relations. Journal of Law and Economics, 22(2), 233-261.

Zhang, X., Chan, F. T. S., Adamatzky, A., Mahadevan, S., Yang, H., Zhang, Z., \& Deng, Y. (2017) An intelligent physarum solver for supply chain network design under profit maximization and oligopolistic competition. International Journal of Production Research, 55(1), 244-263.

Recebido: Abril 03, 2017

Aceito: Agosto 17, 2018

Como citar: Palmieri, F. G., \& Boteon, M. (2018) A percepção do citricultor sobre a indústria paulista de suco de laranja: parceria ou conflito? Citrus Research \& Technology, 39, e1034, https://doi.org/10.4322/crt.39125. 